\title{
Tumor necrosis factor induces doxorubicin resistance to lung cancer cells in vitro
}

\begin{abstract}
Tumor necrosis factor can alter the cell cycle of tumor cells and protect hematopoietic stem cells from cell cycle-specific chemotherapy, but the ability of tumor necrosis factor to protect cancer cells from chemotherapy by manipulation of the cell cycle is unknown. Twenty-four-hour exposure of A549 human lung cancer cells to tumor necrosis factor shifted cells from $S$ phase to $G_{0} / G_{1}$ phase as determined by analysis of isolated cell nuclei with an FACScan Cell Sorter. This effect was not seen in cells exposed to interleukin-1 or interleukin-6. Growth assays demonstrated that tumor necrosis factor slowed the doubling time of $A 549$ cells, confirming that tumor necrosis factor caused $G_{0} / G_{1}$ arrest in these cells. Pretreatment with tumor necrosis factor rendered cells resistant to subsequent 1-hour exposure to doxorubicin, a chemotherapeutic agent active against $S$ phase cells. Tumor necrosis factor did not protect cells against either cisplatin or mitomycin $\mathrm{C}$, drugs not specific for $\mathrm{S}$ phase. Measurement of intracellular drug levels indicated that pretreatment with tumor necrosis factor did not affect doxorubicin uptake or efflux. These findings suggest that cells producing tumor necrosis factor within a tumor may render surrounding malignant cells resistant to cell cycle-specific chemotherapy, and this mechanism may explain failure of sequential immunotherapy-chemotherapy protocols. ( $J$ THORAC Cardiovasc Surg 1994;107:43-9)
\end{abstract}

Thomas W. Prewitt, MD (by invitation), Wilbert Matthews, BS (by invitation), Geeta Chaudhri, PhD (by invitation), Helen W. Pogrebniak, MD (by invitation), and Harvey I. Pass, MD,

Bethesda, Md.

$\mathrm{T}_{\text {he }}$ he growth of a tumor cell is described by a sequential series of events called the cell cycle. ${ }^{1-3}$ The cell cycle is composed of four phases called $\mathrm{G}_{1}, \mathrm{~S}, \mathrm{G}_{2}$, and $\mathrm{M}$ (Fig. 1, $A$ ). Cells that are actively synthesizing deoxyribonucleic acid (DNA) in preparation for cell division are in $S$ phase, and $M$ phase refers to dividing cells in mitosis. The "gap phases," which fall between mitosis and DNA synthesis, are called $G_{1}$ and $G_{2} . G_{2}$ and $M$ phase cells have gone through DNA synthesis and contain double, or $2 \mathrm{~N}$, amounts of DNA, whereas $G_{1}$ cells are the products of cell division and contain $\mathrm{N}$ amounts of DNA (Fig. 1, B). With certain stimuli, cells can be induced to leave the cell cycle, yet remain capable of reentering the cell cycle and

From the Surgery Branch, National Cancer Institute, National Institutes of Health, Bethesda, Md.

Read at the Seventy-third Annual Meeting of The American Association for Thoracic Surgery, Chicago, Ill., April 25-28, 1993.

Address for reprints: Harvey I. Pass, MD, Head, Thoracic Oncology Section, Surgery Branch, National Cancer Institute, National Institutes of Health, Building 10, Room 2B07, 9000 Rockville Pike, Bethesda, MD 20892.

$12 / 6 / 50458$ proceeding through normal cell division., ${ }^{2} 3$ These "resting" or nondividing cells are morphologically the same as $G_{1}$ cells and are said to be in $G_{0}$ phase (Fig. 1). Because $\mathrm{G}_{0}$ and $\mathrm{G}_{1}$ cells contain the same amount of DNA and are difficult to distinguish, resting cells are often referred to as $G_{0} / G_{1}$ cells.

Cell cycle arrest can be achieved by cytokines acting at major control points in $\mathrm{G}_{1},{ }^{4,5}$ including tumor necrosis factor (TNF) ${ }^{6,7}$ Several studies have shown that cells arrested in $\mathrm{G}_{0} / \mathrm{G}_{1}$ by TNF are protected against subsequent cytotoxic insults. Cell cycle arrest in $G_{0} / G_{1}$ by TNF can protect hematopoietic stem cells against radiation and cell cycle-specific cytotoxic chemotherapy. ${ }^{8,9}$ Moreover, TNF induces radioresistance in mice, possibly by a similar mechanism. ${ }^{10-12}$ Little is known, however, about the potential for TNF to protect cancer cells from chemotherapeutic agents by $\mathrm{G}_{0} / \mathrm{G}_{1}$ arrest.

Resistance to cytotoxic chemotherapy is a common cause of treatment failure in patients with advanced nonsmall-cell lung cancer. Although doxorubicin, an anthracycline antibiotic, is active against non-small-cell lung cancer in vitro, overall clinical response rates are less than 


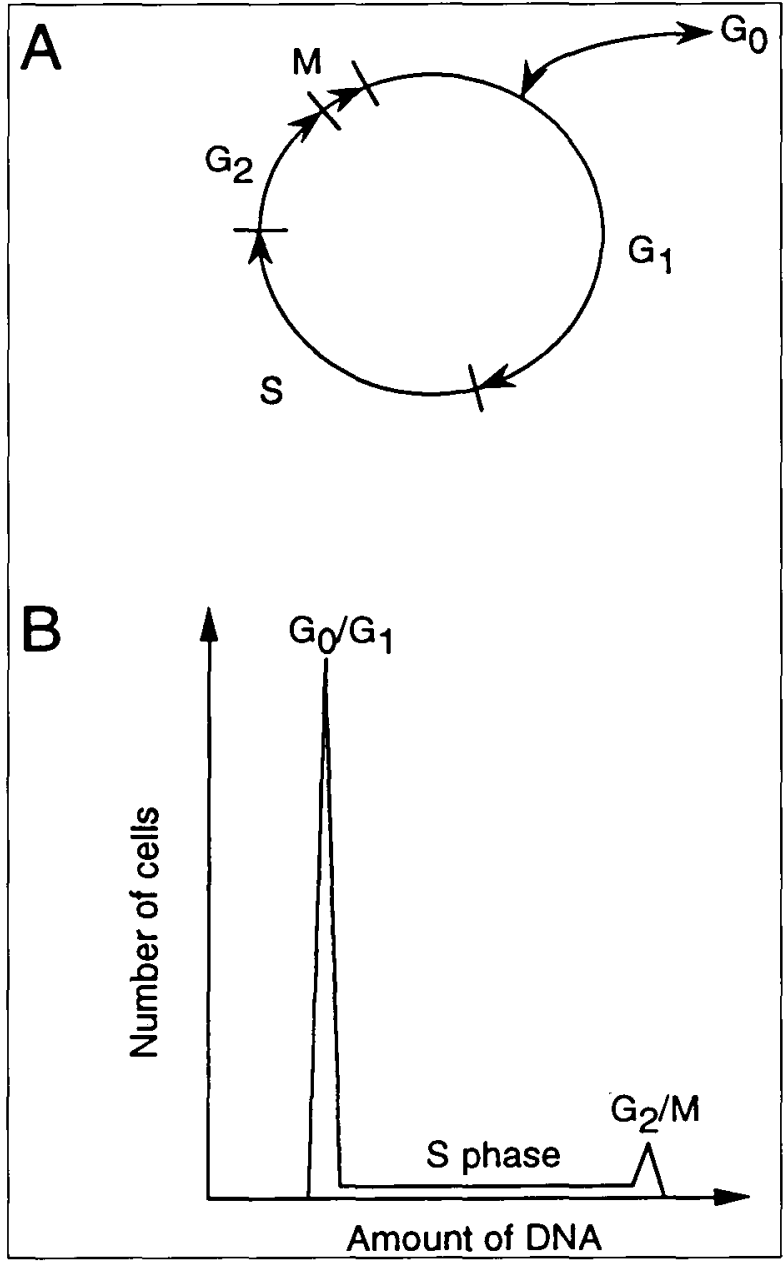

Fig. 1. A, Phases of the mammalian cell cycle. $G_{l}$ and $G_{2}$ represent the "gap" phases between DNA synthesis $(S)$ and mitosis $(M)$. Cytokines such as TNF can cause cells to enter the "resting" phase $\left(G_{0}\right)$, where they can remain quiescent for an indefinite period, reentering the cell cycle after appropriate stimuli. B, Representation of DNA histogram obtained by analysis with an FACScan Cell Sorter. Staining cell nuclei with propidium iodide allows measurement of the number of events (vertical axis) at a given level of fluorescence (horizontal axis). $G_{0}$ and $G_{1}$ cells contain $N$ amount of DNA, $G_{2}$ and $M$ cells contain $2 \mathrm{~N}$ DNA, and $\mathrm{S}$ phase cells contain between $\mathrm{N}$ and $2 \mathrm{~N}$ DNA.

$20 \%$ when doxorubicin is used as single-agent chemotherapy. ${ }^{13}$ In vitro, doxorubicin exerts greater effects on exponentially growing cells than on resting cells. ${ }^{14}$ Therefore, because TNF inhibits growth of lung cancer cell lines, ${ }^{15}$ we hypothesized that lung cancer cells may become resistant to doxorubicin after cell cycle changes induced by TNF exposure. Because tumors contain a variety of nonmalignant cells that secrete TNF, such as tumor-associated macrophages, ${ }^{16}$ this effect could explain the resistance of some types of cancer to chemotherapy.

\section{Materials and methods}

Cell culture. A549 human lung adenocarcinoma cells were obtained from American Tissue Culture Collection (Rockville, Md.). The cell line was passaged and maintained in RPMI medium (Roswell Park Memorial Institute, Buffalo, N.Y.) supplemented with $10 \%$ fetal calf serum, $0.03 \%$ glutamine, and $2 \%$ penicillin-streptomycin solutions (Biofluids, Inc., Rockville, Md.). Cultures were maintained at $37^{\circ} \mathrm{C}$ in a humidified atmosphere of 5\% carbon dioxide and $95 \%$ air. Exponentially growing cells were used in all experiments.

Chemicals. Recombinant human TNF was supplied by Genentech (San Francisco, Calif.), and recombinant human interleukin-1 (IL-1) was supplied by Hoffmann-La Roche, Inc. (Nutley, N.J.). Recombinant human IL-6 was purchased from Endogen (Boston, Mass.). Doxorubicin, cisplatin, and mitomycin $\mathrm{C}$ were purchased from Sigma Chemical Co. (St. Louis, Mo.).

Flow cytometric DNA analysis. A549 cells were incubated in $100 \mathrm{~mm}$ plastic dishes (Costar, Cambridge, Mass.) in various concentrations of TNF, IL-1, or IL-6 for 24 hours, harvested with trypsin-versene solution (Biofluids), and washed in RPMI medium. The pellet was resuspended in $0.2 \mathrm{ml}$ cell lysis citrate buffer containing spermine for nuclear stabilization. ${ }^{17,18}$ After 10 minutes' incubation at room temperature, $2.0 \mathrm{ml}$ trypsin inhibitor solution containing ribonuclease-A (Sigma) was added to obtain isolated nuclei. The solutions were resuspended, incubated at room temperature, and filtered through a $30 \mu \mathrm{m}$ nylon mesh. The nuclei were then stained with propidium iodide solution (Sigma). The samples were analyzed by flow cytometry with an FACScan 3 Cell Sorter, and the cell cycle data were analyzed by CELLFIT program software (BectonDickinson, Sunnyvale, Calif.). This experiment was repeated four times.

Growth assays. Cells were plated in T-25 flasks (Nunc, Roskilde, Denmark) at a density of 20,000 cells in $3.0 \mathrm{ml}$ per flask. After overnight incubation, medium was replaced with fresh medium containing TNF at various concentrations. Cells were harvested with trypsin-versene solution on day 3 and counted on a Coulter cell counter (Coulter Electronics, Hialeah, Fla.). This experiment was performed three times with duplicate values for each time point.

Clonogenic assays. A total of 500,000 cells were plated in $100 \mathrm{~mm}$ plastic dishes (Costar) and incubated overnight. Medium was then replaced with medium containing various concentrations of TNF. After a 24-hour incubation, the TNF was removed and the cells were washed and then exposed to doxorubicin, mitomycin $\mathrm{C}$, or cisplatin at various concentrations for 1 hour. The drug-containing media were removed, and the cells were washed three times with phosphate-buffered saline solution. The cells were then harvested with trypsin-versene solution, suspended in complete media, centrifuged, resuspended, and counted with a Coulter counter. Cell via bility as assessed by trypan blue staining correlated closely with the counts obtained with the Coulter counter. Cells were then serially diluted and plated in $100 \mathrm{~mm}$ and $60 \mathrm{~mm}$ plastic culture dishes (Costar) at densities of $100,000,5000$, and 250 cells per plate. The plated cells were allowed to develop colonies over an 8-day 


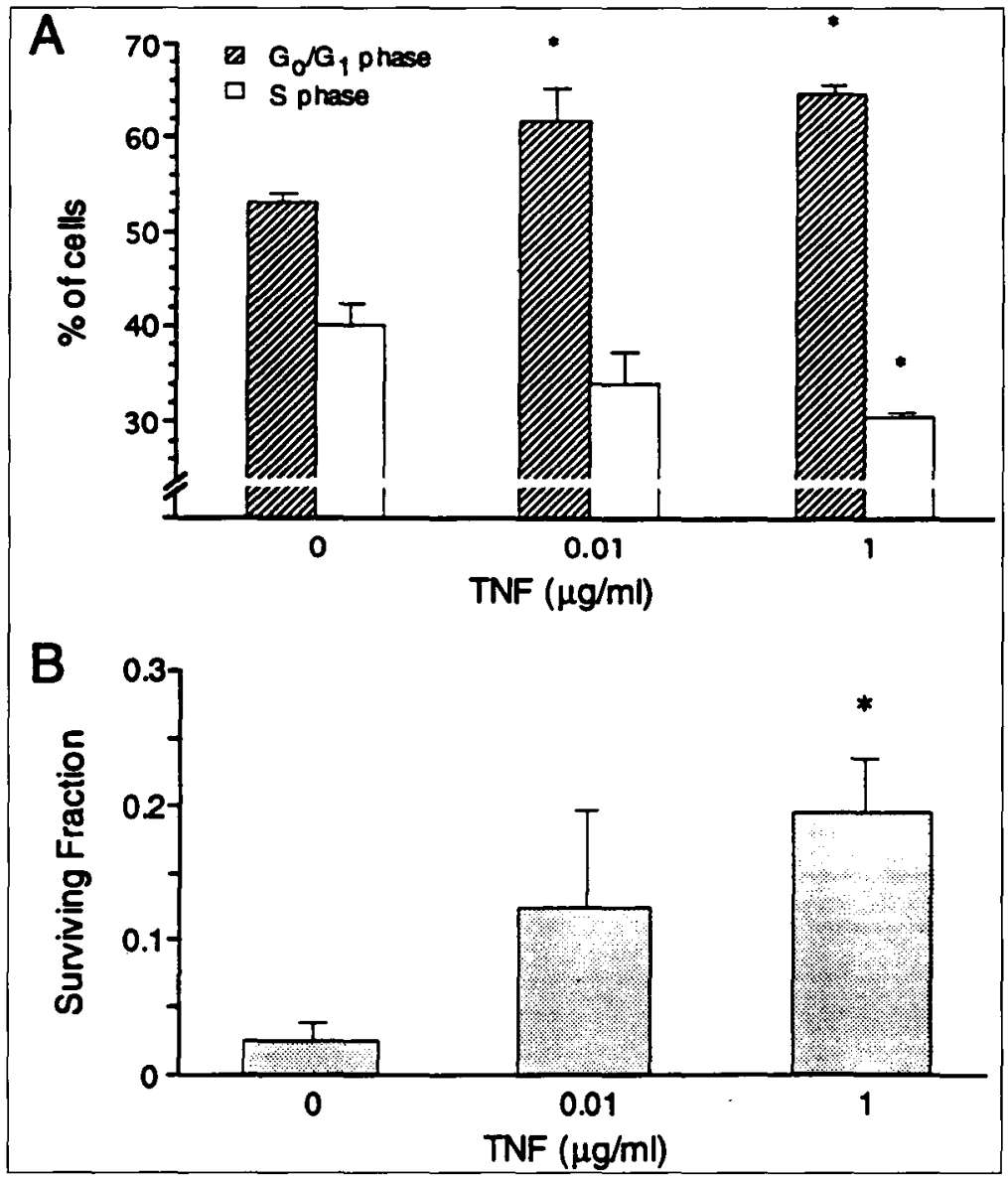

Fig. 2. A, Cell cycle effects of TNF. Twenty-four-hour exposure of A549 cells to TNF caused a shift from S phase to $\mathrm{G}_{0} / \mathrm{G}_{1}$ phase. B, Effect of TNF pretreatment on sensitivity to doxorubicin. A549 cells pretreated with varying concentrations of TNF were less sensitive to subsequent 1 -hour treatment with doxorubicin $5 \mu \mathrm{mol} / \mathrm{L}\left({ }^{*} p_{2}<0.05\right.$ versus 0 TNF).

interval after which they were fixed in 3:1 methanol/acetic acid solution and stained with crystal violet. Colonies of more than 50 cells were then counted under a microscope, and a plating efficiency was calculated as the number of colonies divided by the number of cells plated. Survival fractions were calculated by dividing the plating efficiency of drug-treated cells by the plating efficiency of untreated control cells. Triplicate values were obtained from each experiment, and each experiment was repeated at least three times.

Measurement of TNF influence on intracellular doxorubicin content. Intracellular doxorubicin levels were measured by fluorescence spectrophotometry. Briefly, 100,000 A549 cells were plated in $100 \mathrm{~mm}$ plastic dishes and incubated overnight. Cells were then exposed to TNF $1.0 \mu \mathrm{g} / \mathrm{ml}$ or medium alone for 24 hours. After removal of medium, cells were then exposed to doxorubicin $10 \mu \mathrm{mol} / \mathrm{L}$ for various durations. Cells were washed, harvested with trypsin-versene solution, centrifuged, resuspended in saline solution, and counted on a Coulter counter. Cells were then centrifuged and resuspended in a 1:1 mixture of alcohol $/ 0.3 \mathrm{~N}$ hydrochloric acid to extract intracellular doxorubicin. After the solution was mixed vigorously in a vortex, a fluorescence spectrophotometer was used to measure the relative fluorescence of each sample at an excitation wavelength of $479 \mathrm{~nm}$ and an emission wavelength of $593 \mathrm{~nm}$. Results were expressed as the relative fluorescence per 100,000 cells. The experiment was repeated three times.

Statistical analysis. Results were expressed as means \pm standard errors. Student's paired $t$ test was used to compare mean values. ${ }^{19}$ Results were considered statistically significant for $p_{2}<0.05$.

\section{Results}

Effects of cytokines on cell cycle and growth of A549. The effect of a 24-hour exposure of various cytokines on A549 cell cycling was evaluated by determination of the DNA content of nuclei isolated from cytokine-exposed cells with an FACScan Cell Sorter. This revealed that TNF caused an increase in the number of cells in $\mathrm{G}_{0} / \mathrm{G}_{1}$ phase, with a corresponding decrease in cells in $\mathrm{S}$ phase (Fig. 2, $A$ ). The cell cycle effects of TNF were con- 

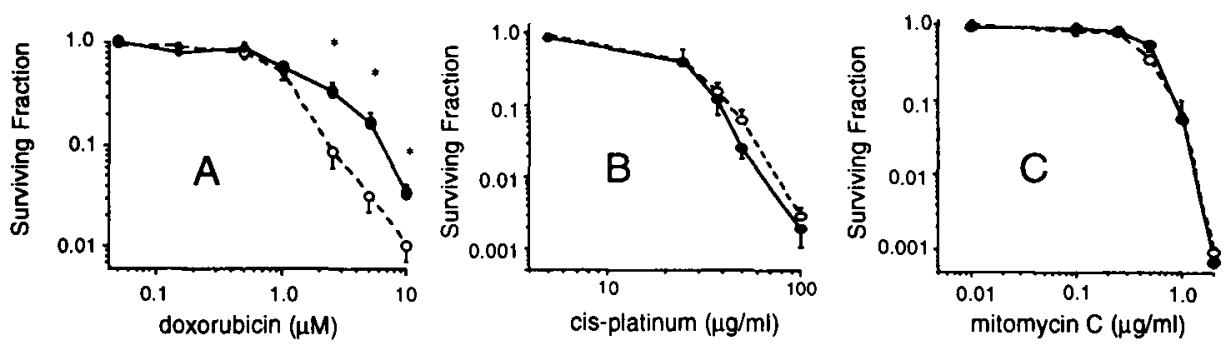

$\rightarrow-$ TNF pretreatment $\quad-\mathrm{O}-$ no TNF pretreatment

Fig. 3. Effect of 24-hour pretreatment with $T N F 1.0 \mu \mathrm{g} / \mathrm{ml}$ on sensitivity of A549 cells to varying concentrations of doxorubicin, cisplatin, and mitomycin C. TNF caused cells to become relatively resistant to doxorubicin (A). Cells were not protected against cisplatin $(\mathbf{B})$ or mitomycin $\mathbf{C}(\mathbf{C})\left({ }^{*} p_{2}<0.05\right.$ versus no TNF pretreatment).

firmed by growth assays in which TNF significantly inhibited growth at 72 hours $\left(25 \pm 7 \times 10^{5}\right.$ versus $33 \pm$ $9 \times 10^{5}, \mathrm{TNF} 1.0 \mu \mathrm{g} / \mathrm{ml}$ versus no TNF, $p_{2}=0.03$ ). These experiments showed that TNF concentrations that increased the percentage of cells in the $G_{0} / G_{1}$ resting phase of the cell cycle caused a concordant inhibition of growth of A549 cells. Incubation with IL-1 or IL-6 up to 1000 units $/ \mathrm{ml}$ did not affect the cell cycle of A549 cells, which indicates that the effect was specific for TNF and not generalized to all cytokines (data not shown).

Effects of TNF pretreatment on sensitivity to chemotherapy. After demonstrating that TNF exposure shifts $A 549$ cells to the $G_{0} / G_{1}$ phase of the cell cycle, we investigated the effects of TNF pretreatment on the sensitivity of A549 cells to different chemotherapeutic agents. Twenty-four-hour pretreatment with TNF in varying concentrations resulted in an increase in surviving fraction in A549 cells subsequently exposed to doxorubicin $5000 \mathrm{nmol}$ (Fig. 2, B). We then examined the effect of pretreatment with TNF on chemosensitivity of A549 cells to varying concentrations of doxorubicin, cisplatin, and mitomycin C. Twenty-four-hour pretreatment with TNF $1.0 \mu \mathrm{g} / \mathrm{ml}$ resulted in attenuation of doxorubicin cytotoxicity at doses of $2.5 \mu \mathrm{mol} / \mathrm{L}$ or more (Fig. 3, A). However, TNF pretreatment did not protect cells against two other drugs, cisplatin and mitomycin $C$, which are not cell cycle specific ${ }^{20}$ (Fig. $3, B$ and $C$ ).

Effect of TNF on intracellular doxorubicin levels. We examined the effect of TNF on intracellular doxorubicin levels to eliminate decreased drug uptake and increased drug excretion as possible mechanisms for the attenuated sensitivity to doxorubicin seen in TNF-exposed cells. Levels of doxorubicin in TNF-exposed and control cells were similar during uptake as measured at 15, 30, and 60 minutes (Fig. 4, $A$ ). Likewise, TNF pre- treatment did not cause a decrease in drug levels during the efflux phase at 0 and 1 hour (Fig. 4, B).

\section{Discussion}

Doxorubicin tumor cytoxicity may involve several mechanisms, including topoisomerase-II-dependent DNA damage ${ }^{20}$ Topo II, a nuclear matrix protein that modulates DNA topology and is involved in cell division, shows increased activity in $\mathrm{S}$ phase cells. ${ }^{21}$ Drugs targeted against Topo II are most active against logarithmically growing cells, ${ }^{21-23}$ possibly through cell cycle-dependent mechanisms. ${ }^{24}$ Our data show that 24-hour pretreatment of A549 cells with TNF shifts cells into the $\mathrm{G}_{0} / \mathrm{G}_{1}$ resting phase of the cell cycle, subsequently causing these cells to become resistant to doxorubicin (Figs. 2 and 3). Comparison of doxorubicin toxicity with $\mathrm{S}$ phase percentage at various TNF doses reveals an inverse relationship (Fig. 2), indicating that as the percentage of dividing cells in a population decreases, doxorubicin resistance increases. These TNF-pretreated cells required a twofold increase in doxorubicin concentration to achieve levels of cytoxicity equal to those of non-TNF exposed cells (Fig. 3). The fact that TNF did not protect A549 cells against cisplatin, or mitomycin $\mathrm{C}$, two alkylating agents that are active against cells in all phases of the cell cycle, ${ }^{20}$ gives further evidence that TNF-induced doxorubicin resistance is a cell cycle effect.

Alternative hypotheses for the protective effect of TNF seen in these experiments include increased free radical buffering capacity and decreased intracellular drug levels. Several studies have implicated the involvement of oxygen-derived free radicals in doxorubicin, ${ }^{25-27}$ cisplatin, and mitomycin $\mathrm{C}$ cytoxicity, ${ }^{20}$ and free radical scavengers, particularly glutathione-dependent enzymes, can render cells resistant to these drugs. ${ }^{28-33}$ However, where- 


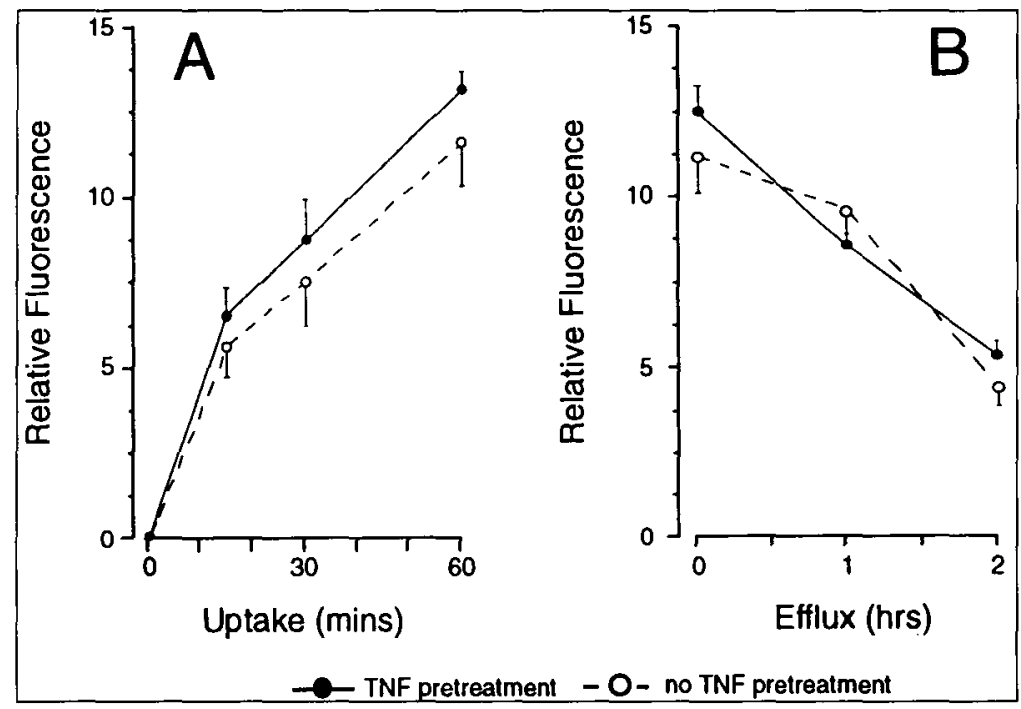

Fig. 4. Effect of TNF pretreatment on intracellular doxorubicin levels. After 24-hour pretreatment with TNF 1.0 $\mu \mathrm{g} / \mathrm{ml}$ and subsequent exposure to doxorubicin $10 \mu \mathrm{mol} / \mathrm{L}$, cells were harvested at various time points, doxorubicin was extracted and measured as described in the Materials and methods section, and doxorubicin concentration was determined by measuring the fluorescence of each sample. Relative fluorescence of TNF-pretreated and control cells indicated that TNF did not affect doxorubicin uptake (A) or efflux (B).

as A549 cells produce increased messenger ribonucleic acid transcripts of the free radical scavenger manganous superoxide dismutase in response to TNF, glutathione levels are unchanged. ${ }^{34}$ In addition, TNF pretreatment did not protect cells against either mitomycin $\mathrm{C}$ or cisplatin (Fig. 3), which suggests that increased buffering capacity alone does explain TNF-mediated doxorubicin resistance.

Decreased intracellular drug accumulation is another potential mechanism for TNF-induced doxorubicin resistance. The phenomenon of multidrug resistance as mediated by the P-170 glycoprotein is a common cause of doxorubicin resistance in cancer chemotherapy. ${ }^{13}$ Doxorubicin-resistant cell lines that express the multidrug resistance phenotype can be developed under selective pressure of continuous doxorubicin exposure. Resistant cells will actively pump drug out of the cell, resulting in much lower intracellular drug levels than the parent cell line. Our data indicate that this mechanism is not involved in TNF-induced doxorubicin resistance, because TNF pretreatment did not cause reduced intracellular doxorubicin levels (Fig. 4).

The A549 cell line was used because of its excellent plating efficiency, which lends this line to survival analysis by clonogenic assays. Its inherent in vitro chemosensitivity and radiation sensitivity have been explored in the past. Although it is likely that the observations seen here would apply to other lung cancer cell lines, it is of great interest to see whether cell lines of varying non-small-cell histologic types act in a similar fashion.

In summary, we have shown that TNF pretreatment renders A549 lung cancer cells resistant to the chemotherapeutic agent doxorubicin in vitro by shifting cells to the $\mathrm{G}_{0} / \mathrm{G}_{1}$ resting phase of the cell cycle. This finding implies that inflammatory cells that elaborate TNF, such as tumor-associated macrophages, ${ }^{16}$ might confer doxorubicin resistance to surrounding tumor cells. Exposure to doxorubicin while in $G_{0} / G_{1}$ might then promote the multidrug resistance phenotype in tumor cells or increase production of free radical buffering enzymes and enable the cells to retain doxorubicin resistance on reentering the cell cycle. Although another recent report indicates that other factors elaborated by macrophages can render cells resistant to doxorubicin, ${ }^{35}$ further studies are necessary to determine the role of TNF and other cytokines in drug resistance. The increased resistance of the cell line to subsequent treatment with doxorubicin may have direct clinical applicability, for if patients are treated with innovative trials involving immunotherapy either directly with TNF or with cytokines whose mechanism may be linked to TNF (i.e., IL-2), it may be possible that short-term doxorubicin resistance could be imparted to certain clones. This would be particularly hazardous in combination immunotherapy-chemotherapy trials. Neverthe- 
less, the effect may be time limited and may have little importance. The potential to answer clinical relevancy of the in vitro findings can be pursued in vivo with the use of immunodeficient animals.

\section{REFERENCES}

1. Kirschner MW. The biochemical nature of the cell cycle. In: Important Advances in Oncology. DeVita VT, Hellman S, Rosenberg S, eds. Philadelphia: JB Lippincott, 1992:316.

2. Pardee $A B . G_{1}$ events and regulation of cell proliferation. Science 1989;246:603-8.

3. Gelfant S. A new concept of tissue and tumor cell proliferation. Cancer Res 1977;37:3845-62.

4. O'Connor PM, Kohn KW. A fundamental role for cell cycle regulation in the chemosensitivity of cancer cells? Cancer Biol 1992;3:409-16.

5. Kimchi A. Cytokine triggered molecular pathways that control cell cycle arrest. J Cell Biochem 1992;50:1-9.

6. Sgagias MK, Kasid A, Danforth DN Jr. Interleukin-1 alpha and tumor necrosis factor-alpha inhibit growth and induce TNF messenger RNA in MCF-7 human breast cancer cells. Mol Endocrinol 1991;5:1740-7.

7. Yarden A, Kimchi A. Tumor necrosis factor reduces c-myc expression and cooperates with Interferon-gamma in HeLa cells. Science 1992;234:1419-21.

8. Warren DJ, Slordal L, Moore MA. Tumor necrosis factor induces cell cycle arrest in multipotential hematopoietic stem cells: a possible radioprotective mechanism. Eur $\mathrm{J}$ Haematol 1990;45:158-63.

9. Slordal L, Warren DJ, Moore MA. Protective effects of tumor necrosis factor on murine hematopoiesis during cycle-specific cytotoxic chemotherapy. Cancer Res 1990; 50:4216-20.

10. Neta R, Oppenheim JJ, Douches SD. Interdependence of the radioprotective effects of human recombinant interleukin-1 alpha, tumor necrosis factor alpha, granulocyte colony-stimulating factor, and murine recombinant granulocyte-macrophage colony-stimulating factor. J Immunol 1988;140:108-11.

11. Neta R, Oppenheim JJ, Schreiber RD, Chizzonite R, Ledney GD, MacVittie TJ. Role of cytokines (interleukin 1, tumor necrosis factor, and transforming growth factor beta) in natural and lipopolysaccharide-enhanced radioresistance. J Exp Med 1991;173:1177-82.

12. Slordal L, Warren DJ, Moore MA. Effect of recombinant murine tumor necrosis factor on hemopoietic reconstitution in sublethally irridiated mice. J Immunol 1989;142:833-5.

13. Gottesman M. How cancer cells evade chemotherapy: sixteenth Richard and Hinda Rosenthal Foundation Award Lecture. Cancer Res 1993;53:747-54.

14. Barranco SC. Review of the survival and cell kinetics of Adriamycin (NSC-123127) on mammalian cells. Cancer Chemother Reports Part 3 1975;6:147-52.

15. Munker M, Munker R, Saxton RE, Koeffler HP. Effect of recombinant monokines, lymphokines, and other agents on clonal proliferation of human lung cancer cell lines. Cancer Res 1987;47:4081-5.

16. Mantovani A, Bottazzi B, Colotta F, Sozzani S, Ruco L. The origin and function of tumor-associated macrophages. Immunol Today 1992;13:265-70.

17. Vindelov LL, Christenson IJ, Nissen NI. Standardization of high-resolution flow cytometric DNA analysis by the simultaneous use of chicken and trout red blood cells as internal standards. Cytometry 1983;3:323-7.

18. Vindelov LL, Christenson IJ, Nissen NI. A detergenttrypsin method for the preparation of nuclei for flow cytometric DNA analysis. Cytometry 1983;3:323-7.

19. Colton T. Statistics in medicine. 1st ed. Boston: Little Brown, 1974.

20. Myers CE, Chabner BA. Anthracyclines. In: Devita VT, Hellman S, Rosenberg SA, eds. Cancer: principles and practice of oncology. 3rd ed. Philadelphia: JB Lippincott, 1989:356-81.

21. Sullivan DM, Ross WE. Resistance to inhibitors of DNA topoisomerases. In: Ozols RF, ed. Molecular and clinical advances in anticancer drug resistance. Boston: Kluwer Academic Publishers, 1991:57-99.

22. Liu L, D'Arpa P: Topoisomerase-targeting antitumor drugs: mechanisms of cytotoxicity and resistance. Philadelphia: JB Lippincott, 1992:79-89.

23. Markovits J, Pommier Y, Kerrigan D, Covey JM, Tilchen EJ, Kohn KW. Topoisomerase II-mediated DNA breaks and cytotoxicity in relation to cell proliferation and the cell cycle in NIH 3T3 fibroblasts and L1210 leukemia cells. Cancer Res 1987;2050-5.

24. Lee FYF, Flannery DJ, Siemann DW. Modulation of the cell cycle-dependent cytoxicity of Adriamycin and 4-hydroxyperoxycyclophosphamide by novobiocin, an inhibitor of mammalian topoisomerase II. Cancer Res 1992;52: 3515-20.

25. Sinha BK, Minnaugh EG. Free radicals and anticancer drug resistance: oxygen free radicals in the mechanisms of drug cytoxicity and resistance by certain tumors. Free Radical Biol Med 1990;8:567-81.

26. Doroshow JH. Role of hydrogen peroxide and hydroxyl radical formation in the killing of Ehrlich tumor cells by anticancer quinones. Proc Natl Acad Sci USA 1986;83: 4514-8.

27. Doroshow JH. Prevention of doxorubicin-induced killing of MCF-\& human breast cancer cells by oxygen radical scavengers and iron chelating agents. Biochem Biophys Res Commun 1986;135:330-5.

28. Batist G, Tulpule A, Sinha BK, Katki AG, Myers CE, Cowan KH. Overexpression of novel anionic glutathione transferase in multidrug-resistant human breast cancer cells. J Biol Chem 1986;261:15544-9.

29. Sinha BK, Katki AG, Batist G, Cowan KH, Myers CE. Adriamycin-stimulated hydroxyl radical formation in human breast tumor cells. Biochem Pharmacol 1987;36: 793-6. 
30. Minnaugh EG, Dusre L, Atwell J, Myers CE. Differential oxygen radical susceptibility of Adriamycin-sensitive and resistant MCF-7 human breast tumor cells. Cancer Res 1989;49:8-15.

31. Fraval HNA, Roberts JJ. G1 phase Chinese hamster V79379A are inherently more sensitive to platinum bound to their DNA than mid S phase or asynchronously treated cells. Biochem Pharmacol 1979;28:1575-80.

32. Anderson ME, Naganuma A, Meister A. Protection against cisplatin toxicity by administration of glutathione ester. FASEB J 1990;4:3251-5.

33. Krishna MC, DeGraff W, Tamura S, et al. Mechanisms of hypoxic and aerobic cytoxicity of mitomycin $C$ in chinese hamster V79 cells. Cancer Res 1991;51:6622-8.

34. Wong GHW, Goeddel DV. Induction of manganous superoxide dismutase by tumor necrosis factor: possible protective mechanism. Science 1988;242:941-4.

35. Hacker MP, Kimberly PJ, Gundel RM, Huot AE. Induc- tion of transient resistance to doxorubicin in tumor cells exposed to nitric oxide secreted by activated macrophages. Proc AACR 1992;33:423.

\section{Discussion}

Dr. Martin F. McKneally (Toronto, Ontario, Canada). Dr. Prewitt, is there a way that you can take advantage of this seemingly negative effect, for example, by synchronizing cells and then restarting them once you have stopped the cell cycle?

Dr. Prewitt. Theoretically, TNF could be used to arrest cells arrested in $G_{0} / G_{1}$ and then stimulated to reenter the cell cycle as a synchronized population. Treatment with an $\mathrm{S}$ phase-specific drug such as doxorubicin while the synchronized cells are synthesizing DNA could increase the chemotherapeutic effect, because a much larger population of cells would be sensitive to the drug. However, in vivo synchronization of cancer cells has not yet been accomplished and remains an area of active investigation in the field of cell cycle research. 